SCIENTIFIC LETTER

\title{
Cycle exercise causes a lower ventilatory response to exercise in chronic heart failure
}

\author{
K K A Witte, A L Clark
}

Heart 2005;91:225-226. doi: 10.1136/hrt.2003.026567

$\mathrm{P}$ atients with chronic heart failure (CHF) complain of breathlessness and fatigue. Their exercise limitation can be assessed by incremental exercise testing with metabolic gas exchange to derive peak oxygen consumption $\left(\mathrm{pV}^{\circ} \mathrm{O}_{2}\right)$. The slope of the relation between ventilation $(\dot{\mathrm{V}} \mathrm{E})$ and carbon dioxide production $\left(\dot{\mathrm{V}} \mathrm{CO}_{2}\right), \dot{\mathrm{V}} \mathrm{E} / \dot{\mathrm{V}}_{\mathrm{CO}}$ can characterise the ventilatory response to exercise. CHF patients have a reduced $\mathrm{p} \dot{\mathrm{V}}_{2}$ and an increased $\dot{\mathrm{V}} \mathrm{E} / \dot{\mathrm{V}} \mathrm{CO}_{2}$ slope. ${ }^{1}$ Thus, for a given $\dot{\mathrm{V}} \mathrm{CO}_{2}$, the ventilatory response is greater. These two measures are inversely related in patients, but not controls, and both are related to prognosis.

The form of exercise undertaken, stationary cycle or treadmill, varies between exercise laboratories. Treadmill based protocols achieve higher values of $\mathrm{p} \dot{\mathrm{V}}_{2}$ and anaerobic threshold than those using a cycle. The effects of the different exercise modes on the $\dot{\mathrm{V}} / \mathrm{V}_{\mathrm{CO}}$ slope and the symptoms of breathlessness are unknown. The aim of the present study was to explore the effect of cycle and treadmill exercise on ventilation and symptoms.

\section{METHODS}

Eleven patients with CHF and 11 age matched controls were studied. The patients all had New York Heart Association (NYHA) functional class II symptoms, an ejection fraction $<40 \%$ on echocardiography, and all had been stable for the preceding three months on optimal doses of angiotensin converting enzyme inhibitors and $\beta$ blockers. Patients with other conditions restricting exercise testing were excluded. The controls were individuals of a similar age chosen at random from the lists of local general practitioners. They all had normal systolic and diastolic left ventricular function.

After an initial familiarisation test, each subject was randomised to undergo either a treadmill or cycle peak exercise test and to return at one week for a second test using the other exercise mode. For the treadmill test we used the Bruce protocol modified by the addition of a "stage 0 " at onset consisting of three minutes of exercise at $1.61 \mathrm{~km} /$ hour ( 1 mile/hour) with a $5 \%$ gradient. For the cycle test (Rehcor, Cardiokinetics, Salford, UK) the load was increased by $25 \mathrm{~W}$ every three minutes after an initial unloaded stage until the subject was exhausted.

During each test, expired air was collected continuously and metabolic gas exchange analysis performed (Oxycon system, Jaeger, Würtzburg, Germany). Subjects were encouraged to exercise to exhaustion and a respiratory exchange ratio (RER) $\left(\dot{\mathrm{V}} \mathrm{CO}_{2} / \dot{\mathrm{V}}_{2}\right)>1$ was taken to suggest a maximal effort. For each test we plotted the relation of $\dot{\mathrm{V}} \mathrm{E}$ against $\dot{\mathrm{V}} \mathrm{CO}_{2}$, to determine $\dot{\mathrm{V}} \mathrm{E} / \dot{\mathrm{V}} \mathrm{CO}_{2}$ slope.

During each test the subjects were asked to score their symptoms of breathlessness or fatigue between 0 and $10(0$ being no symptoms and 10 being maximal) on a standard scale of perceived exertion (Borg score) at the end of each stage during the test. We plotted Borg score against $\dot{V}_{\mathrm{E}}$ at the end of each stage to obtain a slope for the relation between symptoms and ventilation (Borg/VE slope). ${ }^{2}$
Results are reported as mean (SD). Between the visits, no subject had a change of medication, or underwent any formal exercise training. For within group analyses we used Student's paired $t$ test, and to display the differences for variables between the two exercise modalities we used the Bland-Altman analysis (the difference between two variables plotted against their average). Analysis of staged data only included subjects who completed the stage. The reason given by the subjects for discontinuing exercise was compared between the two tests by a $\chi^{2}$ test.

\section{RESULTS}

The patients and controls had similar mean height, weight, and age. Patients had lower $\mathrm{p} \dot{\mathrm{V}} \mathrm{O}_{2}$, and a steeper $\dot{\mathrm{V}} \mathrm{E} / \dot{\mathrm{V}}_{\mathrm{CO}_{2}}$ slope than controls (table 1). The slope relating heart rate to oxygen consumption was less steep in the patients when they exercised on the cycle ergometer. Both groups reached significantly lower $p \dot{V}_{2}$ on the cycle than on the treadmill, despite the peak RER being the same. The reduction in $\mathrm{pV}_{\mathrm{O}_{2}}$ on the cycle was $16.2 \%(8.1)$ in the patients and $18.6 \%(10.2)$ in the controls. The difference in reductions between the two groups was significant $(\mathrm{p}<0.05)$. The $\dot{\mathrm{V}} \mathrm{E} / \mathrm{V}_{\mathrm{CO}}$ slope and $\mathrm{pV}_{2}$ from the two methods correlated $(r=0.87$, $\mathrm{p}<0.0001$, and $r=0.94, \mathrm{p}<0.0001)$, but Bland-Altman plots confirmed that in patients the treadmill gave consistently higher readings for $\mathrm{p}_{\mathrm{V}} \mathrm{O}_{2}$ and $\dot{\mathrm{V}} \mathrm{E} / \dot{\mathrm{V}}_{\mathrm{CO}_{2}}$ slope than the cycle ergometer. Although the control subjects achieved a higher $\mathrm{pV}_{\mathrm{O}_{2}}$ on the treadmill, unlike the patients, their $\dot{\mathrm{V}} \mathrm{E} / \dot{\mathrm{V}}_{2}$ slope was not significantly greater during treadmill exercise.

Patients were more symptomatic for a given ventilation (Borg/VE slope) than controls throughout both the cycle and treadmill exercise. There was no difference in the Borg/VE slopes between the two exercise modalities. Cycle based exercise led to patients and controls stopping exercise more frequently because of fatigue rather than breathlessness ( $15 \mathrm{v}$ 7 for cycle and $10 v 12$ for treadmill, $\mathrm{p}<0.05$ ).

\section{DISCUSSION}

This study demonstrates that the $\dot{\mathrm{V}} \mathrm{E} / \dot{\mathrm{V}} \mathrm{CO}_{2}$ slope is less steep when patients exercise on a cycle ergometer than when they exercise on a treadmill and that this difference exists throughout exercise. This has not been described before. Peak oxygen consumption is known to be lower during cycle exercise. The difference is because subjects carry their own weight during walking.

Both $\mathrm{p} \dot{\mathrm{V}}_{2}$ and $\dot{\mathrm{V}} / \dot{\mathrm{V}}_{\mathrm{CO}_{2}}$ slope are independent markers of prognosis and are indirectly related to each other, with lower $\mathrm{p}_{\mathrm{V}} \mathrm{O}_{2}$ and a greater ventilatory response to exercise conveying a worse prognosis. The inverse relation between these two

Abbreviations: $\mathrm{CHF}$, chronic heart failure; $\dot{\mathrm{V}} \mathrm{CO}_{2}$, carbon dioxide production; $p \dot{V}_{2}$, peak oxygen consumption; RER, respiratory exchange ratio; $\dot{\mathrm{V}} \mathrm{E}$, ventilation 
Table 1 Peak exercise variables comparing results from treadmill and cycle

\begin{tabular}{|c|c|c|c|c|}
\hline & Group & Treadmill & Cycle & p Value \\
\hline \multirow{2}{*}{$\mathrm{p} \dot{\mathrm{O}_{2}}(\mathrm{ml} / \mathrm{kg} / \mathrm{min})$} & Patient & 21.1 (5.5) & $18.2(3.6)$ & 0.0012 \\
\hline & Control & $45.9(13.2)^{*}$ & $36.0(9.5)^{*}$ & 0.003 \\
\hline \multirow{2}{*}{ AT $(\mathrm{ml} / \mathrm{kg} / \mathrm{min})$} & Patient & $15.7(5.2)$ & $11.9(2.3)$ & 0.01 \\
\hline & Control & $26.5(9.7)^{*}$ & $27.1(10.0)^{*}$ & 0.47 \\
\hline \multirow{2}{*}{$\dot{\mathrm{V}} \mathrm{E} / \dot{\mathrm{V}} \mathrm{CO}_{2}$ slope } & Patient & $35.3(8.7)$ & $32.0(7.5)$ & 0.0012 \\
\hline & Control & $28.2(5.8) \dagger$ & $26.8(2.1) \dagger$ & 0.792 \\
\hline \multirow{2}{*}{ Sub $\dot{\mathrm{V}} \mathrm{E} / \dot{\mathrm{V}} \mathrm{CO}_{2}$ slope } & Patient & $34.0(7.7)$ & $30.7(6.9)$ & 0.011 \\
\hline & Control & $25.3(4.5) \dagger$ & $25.9(5.0) \dagger$ & 0.69 \\
\hline \multirow{2}{*}{$\mathrm{HR} / \dot{\mathrm{V}}_{2}$ slope } & Patient & $1.68(0.23)$ & $1.50(0.24)$ & 0.024 \\
\hline & Control & $1.86(0.13) \dagger$ & $1.71(0.31) \dagger$ & 0.068 \\
\hline \multirow{2}{*}{ Peak $\dot{V}_{E}(I / \mathrm{min})$} & Patient & 70.7 (15.9) & 54.7 (11.9) & 0.0045 \\
\hline & Control & $109.0(23.7)^{*}$ & $97.3(32.1)^{*}$ & 0.1125 \\
\hline \multirow{2}{*}{ RER } & Patient & $1.05(0.07)$ & $1.03(0.06)$ & 0.64 \\
\hline & Control & $1.03(0.05) \ddagger$ & $1.03(0.11) \ddagger$ & 0.80 \\
\hline \multirow{2}{*}{ Borg/V̈E slope } & Patient & $0.16(0.05)$ & $0.18(0.06)$ & 0.46 \\
\hline & Control & $0.09(0.03) \S$ & $0.11(0.04) \S$ & 0.32 \\
\hline
\end{tabular}

variables is not significantly influenced by the mode of exercise.

The $\dot{\mathrm{V}} \mathrm{E} / \dot{\mathrm{V}}_{\mathrm{CO}}$ slope is influenced by a combination of chemoreceptors, ${ }^{3}$ and muscle receptors (ergoreceptors). ${ }^{4}$ The increased $\dot{\mathrm{V}} / \dot{\mathrm{V}}_{\mathrm{CO}_{2}}$ relationship in CHF is often assumed to be caused by an increase in dead space ventilation, but exercise in the present study was performed in a similar upright position. It is difficult to conclude therefore that dead space can account for changes in the $\dot{\mathrm{V}} \mathrm{E} / \mathrm{V}_{\mathrm{CO}}$ slope in this circumstance. Arm exercise leads to a greater ventilatory response than leg exercise at the same workload. ${ }^{5}$ We hypothesise that during treadmill exercise weight bearing causes greater ergoreflex activation leading to a greater $\dot{V}_{\mathrm{E}}$ for a given $\dot{\mathrm{V}}_{2}$ than when weight is supported.

The Borg/VE slope was the same on the cycle as on the treadmill, suggesting that it might be a measure of symptoms in CHF patients independent of exercise mode. Greater numbers of subjects ceased exercise for leg fatigue than breathlessness on the cycle than on the treadmill, but for a given $\mathrm{p} \dot{\mathrm{V}}_{2}$ the rating of perceived exertion was the same on the treadmill and cycle.

Patients with CHF might have impaired inspiratory muscle strength and endurance. We hypothesised that the seated position might require greater diaphragmatic effort during exercise because of the increased pressure of abdominal contents. However, subjects complained more frequently of fatigue than breathlessness on the cycle, and the Borg/V $\dot{\mathrm{V}}_{\mathrm{E}}$ slope was the same suggesting that the seated position of cycle based exercise does not increase the sensation of the work of breathing.

We conclude that cycle based exercise protocols lead to lower $\mathrm{p} \dot{\mathrm{V}}_{2}$ and $\dot{\mathrm{V}} \mathrm{E} / \dot{\mathrm{V}}_{\mathrm{CO}_{2}}$ slope results and that weight bearing leads to a greater ventilatory response during exercise.

\section{Authors' affiliations}

K K A Witte, A L Clark, Academic Cardiology, Castle Hill Hospital, Hull, UK

Correspondence to: Dr Klaus Witte, Academic Cardiology, Castle Hill Hospital, Castle Road, Cottingham, Hull HU16 5JQ, UK; klauswitte@ hotmail.com

Accepted 28 March 2004

\section{REFERENCES}

1 Buller NP, Poole-Wilson PA. Mechanism of the increased ventilatory response to exercise in patients with chronic heart failure. Br Heart J 1990;63:281-3.

2 Witte KKA Thackray SDR, Nikitin NP, Cleland JGF, Clark AL. The pattern of ventilation during exercise in chronic heart failure. Heart 2003;89:610-4.

3 Narkiewicz K, Pesek CA, van de Borne PJH, et al. Enhanced sympathetic and ventilatory responses to central chemoreflex activation in heart failure. Circulation 1999:100:262-7.

4 Piepoli M, Clark AL, Coats AJS. Muscle metaboreceptors in the hemodynamic, autonomic and ventilatory responses to exercise in man. Am J Physiol 1995;269(Heart Circ Physiol 38):H1428-36.

5 Clark AL, Piepoli M, Coats AJ. Skeletal muscle and the control of ventilation on exercise: evidence for metabolic receptors. Eur J Clin Invest 1995;25:299-305. 